\title{
College Students, Motivation, and Success
}

\author{
Becky J. Cox \\ Educational Studies, The University of Tennessee at Martin \\ 240 B Gooch Hall, Martin, TN 38238, United States \\ Tel: 1-731-881-7143Ｅ-mail: beckyc@utm.edu
}

Accepted: April 2, 2012 Published: May 19, 2012

Doi:10.5296/ijld.v2i3.1818ＵRL: http://dx.doi.org/10.5296/ijld.v2i3.1818

\begin{abstract}
Many people spend a large portion of their lives striving to be successful, chasing success. But what is success? Success means different things to different people. How do we get to be successful? Why do some young adults choose to go to college? Does graduating from college offer a better opportunity for being successful? What motivates college students to go to class day after day, to complete hours of assigned work? What motivates us to be successful? This article reviews the parameters of motivation and what motivation means to different honors-level college students. Additionally, students are asked to determine why they make the choices they do. These topics were the focus in the motivational speech "Think - Understand Succeed" utilizing the \#1 National Bestseller Outliers: The Story of Success by Malcolm Gladwell (2008) as a main reference point. Comparisons were made between real-life situations and those found in Outliers.
\end{abstract}

Keywords: College Students, Success, Motivation, Culture, Family

\section{Introduction}

"Think - Understand - Succeed" required honors-level college students to review their personal experiences to determine why they do what they do. College freshmen come together from various counties, states, and countries to attend classes and mingle closely with other students who may be different from themselves. The college experience is often the first time that young adults have an opportunity to think for themselves, make decisions for themselves, and then reap the consequences of these choices, whether positive or negative. Learning to take a hard, honest look at one's innermost beliefs can be difficult for those who have never really thought for themselves. Reviewing different ideas or beliefs can be challenging to young minds that have not looked at both sides of certain issues. Having an understanding of why we do the 
things we do, think the way we do, and act the way we do leads to actions that prepare us for success.

\section{Literature Review}

Gredler (2005) defines motivation as a process that influences one's choice of and continuance in particular behaviors. Intrinsic motivation, extrinsic motivation, and amotivation are explained by Urdan \& Schoenfelder (2006). Intrinsic motivation is reflected in self-determination and effort. Outside influences such as rewards and punishments characterize extrinsic motivation. Amotivation means the absence of both intrinsic and extrinsic motivation. Research has acknowledged several features affecting motivation, such as family influences, individual enthusiasm, peer influences, and school situations. Additionally, family encouragement and expectations, parental education, and teacher expectations contribute to student efforts (Ames, 1990, Choy, 2001, Urdan \& Schoenfelder, 2006).

Why does anyone decide to enroll in college? Several reasons are commonly accepted and expected: specific career opportunities, ability to support self and family at a certain level, academic aspirations, friendships and networking, family expectations, and a time to discover self (Boatwright, Ching, \& Parr, 1992; Waugh, 2002). Likewise, Corts and Stoner (2011) developed the College Motivation Scale to ascertain what factors played a role in students' choice to attend college. They found that social and career motives correlate with GPA, while self-discovery and academic motives correlate to interest in learning.

Additionally, personality traits and characteristics are often examined in predicting academic performance at the university level. McCrae and Costa (1987) created the "big five" which include conscientiousness $(\mathrm{C})$, neuroticism $(\mathrm{N})$, openness $(\mathrm{O})$, agreeableness $(\mathrm{A})$, and extraversion (E). They decided that of these traits, conscientiousness is the most significant of the academic predictors. Richardson and Abraham (2009) conducted a survey that found conscientiousness is indeed a predictor of GPA for both male and female students.

Likewise, motivation and success are related. Research has found three constants when predicting success, including engagement, academic preparation, and motivation (Adelman, 2004; Kuh et al, 2005; \& Pascarella \& Terenzini, 2005).

\section{Methods}

Therefore, it is generally accepted that motivation and success hold a special relationship. They link together in a way that encourages college students to examine their personal situations and find the way that motivation and success are tied to their lives, in the past, present, and future. This task was accomplished through a talk given to college students being inducted into an honor society in a public university in the southeast. The objective was to provide an opportunity for students to reflect upon their own personal situation and the influences on their life. More specifically, what influenced their choice to become a college student, and to become a college student at this public university? What motivates them to go to class, to write papers and study? Entitled "Think-Understand-Succeed," the content referenced scenarios from Outliers: The Story of Success (Gladwell, 2008). Additionally, personal experiences were interjected at appropriate times. Audience interaction contributed to the event and its perceptions. 
Initially, students were asked to share why they had chosen to enroll at this public university. Several factors were solicited, including "to get a great education, received a scholarship, close to home, far from home, affordability, has specific college for my career interest." Upon further discussion, it was decided the main reason to be a college student is to earn a degree that will lead to success. They reviewed how the family culture played a role in the choice, stating that it was important to be close enough to family that a trip home was possible (or not), and the affordability of a state university with an outstanding reputation was attainable. Additionally, opportunities for scholarships allowed another consideration.

Further conversation led to the understanding that if you have the background knowledge and the experiences, then you understand the situation, and you internalize the knowledge. Those are reasons to think for yourself and be a life-long learner. These qualities will allow you to succeed!

The presentation then turned to Outliers: The Story of Success (Gladwell, 2008, p.3). "outlier: ... noun. 1: something that is situated away from or classed differently from a main or related body. 2: a statistical observation that is markedly different in value from the others of the sample." Students were asked to describe an event that could be considered an outlier using this definition. One student stated that in his hometown, he was considered an outlier, since he had studied hard and was considered a nerd for choosing to get a college education.

Gladwell (2008) shared the story of success of Microsoft creator Bill Gates. As early as middle school, Gates was obsessed with computers. Coming from a wealthy family, Gates was encouraged to work on computers and follow his interests. He was in the right place at the right time, and had wonderful opportunities what he attributed as "an incredibly lucky series of events" (Gladwell, 2008, p. 55). Students agreed that they had been in situations that they could attribute to luck or good fortune. They shared their experiences with former and current instructors and their influences on studies. Interesting teachers made learning more interesting and motivating. They stated that this was especially true in challenging subjects.

Wealthier children receive cultural advantages because parents are more involved in their lives, encouraging them in sports, academic interests, etc. Children from poor families may have natural abilities, but may not receive the support needed to develop even stronger skills (Gladwell, 2008). While sharing experiences of support from parents, families, and teachers, students discussed how their own parents sacrificed in order to provide them with the opportunity to attend college. Being a conscientious student was an important consideration. Several students raised their hands that they are the first person in their family to attend college. They view this opportunity as a personal challenge and plan to graduate and land a job in their chosen fields. They will then be able to "give back" to family and community.

Working adults spend approximately 2,000 hours per year at their place of employment. Bosses want productive employees. Gladwell (2008) states that there are three qualities that most people expect to have in employment if the work is to be satisfying: complexity, autonomy, and a connection between reward and effort. Autonomy is a complex connection 


\section{Macrothink

of effort and reward that makes work meaningful. A common belief is that if you work hard enough and use your mind and imagination, you can shape the world to your desire. Complex work is personally rewarding. Your culture, generation, and family history provide the greatest opportunities for meaningful work. A discussion ensued about choosing your own path, and following your heart to determine your chosen profession. It might be difficult to explain to parents that their chosen career for you might not be what you want to do. However, to be happy and successful in life, you must do what is right for yourself. "Your work is going to fill a large part of your life, and the only way to be truly satisfied is to do what you believe is great work. And the only way to do great work is to love what you do" (Jobs, 2005).

"Our ability to succeed at what we do is powerfully bound up with where we're from..." (Gladwell, 2008, p. 209). In closing, students stated that they appreciated the opportunity to attend college and have the opportunity to be successful in whatever path they chose.

\section{Discussion}

Motivated people are successful people. Motivating factors are different for different people, just as success is defined differently for different people. For honors college students, having an opportunity to earn a college degree leading to a promising career motivate many. Having an opportunity to make parents proud is motivating. Although students are seeking different career paths, they have all learned that success consists of a variety of factors. As they learn to think, they understand; when they understand, they succeed. 


\section{References}

Adelman, C. (2004). Principal Indicators of Student Academic Histories in Postsecondary Education, 1972-2000. Washington, DC: U.S. Department of Education, Institute of Education Sciences.

Ames, C. (1990). Motivation: What teachers need to know. Teachers College Record, 19(3), 409-421.

Boatwright, M.A., Ching, M., \& Parr, A. (1992). Factors that influence students' decisions to attend college. Journal of Instructional Psychology, 19, 79-86.

Choy, S. (2001). Students whose parents did not go to college: Postsecondary access, persistence, and attainment. ED 460660.

Corts, D., \& Stoner, A. (2011). The college motives scale: Classifying motives for entering college. Education, 131(4). 775-781. Retrieved from http://findarticles.com/p/articles/mi_qa3673/is_4_131/ai_n57773359/?tag=content;col1

Gladwell, M. (2008). Outliers: The story of success. New York: Little, Brown, and Co.

Gredler, M. (2005). Learning and Instruction. Theory into Practice. Fifth edition. Pearson Merrill Prentice Hall. Upper Saddle River, New Jersey and Columbus, Ohio.

Jobs, S. (2005). Stanford Commencement address. http://news.stanford.edu/news/2005/june15/jobs-061505.html

Kuh, G., Kinizie, J., Schuh, J., \& Whitt, E. (2005). Student success in college: Assessing the conditions for educational effectiveness. Jossey-Bass.

McCrae, R. R., \& Costa, P. T. (1987). Validation of the 5-factor model of personality across instruments and observers. Journal of Personality and Social Psychology, 52, 81-90.

Pascarella, E., \& Terenzini, P. (2005). How college affects students: A third decade of research. Jossey-Bass.

Richardson, M., \& Abraham, C. (2009). Conscientiousness and achievement motivation predict performance. European Journal of Personality. 23:589-605. Retrieved from www.interscience.wiley.com DOI: 10.1002/per.732.

Urdan, T., \& Schoenfelder, E. (2006). Classroom effects on student motivation: Goal structures, social relationships, and competence beliefs. Journal of School Psychology, 44, 331-349. DOI: 10.1016/jsp.2006.04.003

Waugh, R.F. (2002). Creating a scale to measure motivation to achieve academically: Linking and behaviours using Rasch measurement. British Journal of Educational Psychology, 72, 65-86. DOI: 10.1348/000709902158775 